\title{
Old photographs: postencephalitic Parkinsonism in two small boys
}

\author{
J PURDON MARTIN
}

From the National Hospital for Nervous Diseases, Queen Square, London, UK

SUMMARY My interest in posture and its central nervous control dates from my early days in neurology. That was also the time of the epidemic of encephalitis lethargica. A few years ago I came upon some old photographs dating from this period and among them were several of two small boys suffering from the after-effects of encephalitis with severe disorders of postural control. Each of these boys, if placed on an ordinary chair would let his body fall forward and would "roll" off the chair and lie motionless on the floor. In more recent years it has been shown experimentally that similar symptoms in monkeys are associated with bilateral lesions of the globus pallidus; in post-encephalitic patients of long standing degenerative changes are present in the pallida, but it now seems likely that deficiency of the neuro-transmitter, dopamine, may bear as much responsibility for their symptoms as anatomical lesions. Neurology was slow to appreciate the contribution of the basal ganglia to postural activity.

In my early days in neurology the subject of posture and its central nervous control was very much in the air. Holmes, ${ }^{1}$ in his Croonian lectures of 1922 , gave the classic description of "The clinical symptoms of cerebellar diseases and their interpretation."; Walshe ${ }^{23}$ on his appointment to the honorary staff of the National Hospital, had been given six months leave of absence to go and study with Sherrington and after his return was applying Sherringtonian physiology to the hemiplegics and paraplegics; Magnus and de Kleijn had described various postural reflexes (in the cat) from 1912 onwards, and Magnus's great "Körperstellung", in which they were all brought together, appeared in 1924 and was accorded an eight page review by Walshe 4 in Brain . In such an atmosphere one could hardly fail to develop a lasting interest in the subject.

A few years ago among some old papers I came upon some photographs dating from this period. They were all concerned with posture, and among them were several showing the after-effects of encephalitic lethargica and, in particular, these pictures (fig 1) of two small boys who had been in the hospital at the same time suffering from postencephalitic Parkinsonism with severe postural disturbances. They had been taken by the late Dr WG Wylie, who was at that time RMO at the National Hospital, and afterwards physician to the Hospital

Accepted 25 February 1983 for Sick Children and to Maida Vale Hospital.

Encephalitis lethargica was still prevalent and its numerous and very varied after-effects were becoming known. In the children the usual sequelae were behaviour disorders and disturbances of sleep rhythm, and the Parkinsonian state was not common, and to have two very similar cases in the hospital at the same time was a matter of considerable interest. Unfortunately, the notes of these boys have been lost; what I remember best about them is that each of them, when placed on an ordinary chair, would let his body gradually sink forward and would "roll" off the chair. The first reaction of the nursing staff was to keep the boys in bed when a medical visit was expected, and so the physician, and even the house-physician on his round, might easily remain in ignorance of this peculiar phenomenon. At that time we had no armchairs for the patients to lie back in, let alone the modern harness to hold the incapable ones in position.

It is evident from the photographs that the smaller boy (fig 1) was much more rigid than the other one, and in spite of his rigidity his body sinks down as he stands. I do not know the intervals between the photographs-the clinical cinematograph was still about twenty-five years away-and so it is not possible to say exactly how quickly this occurred, but from the evidence of other cases, it seems likely that it would be no more than a few minutes. The sharpness of the pictures shows that there was no tremor. 

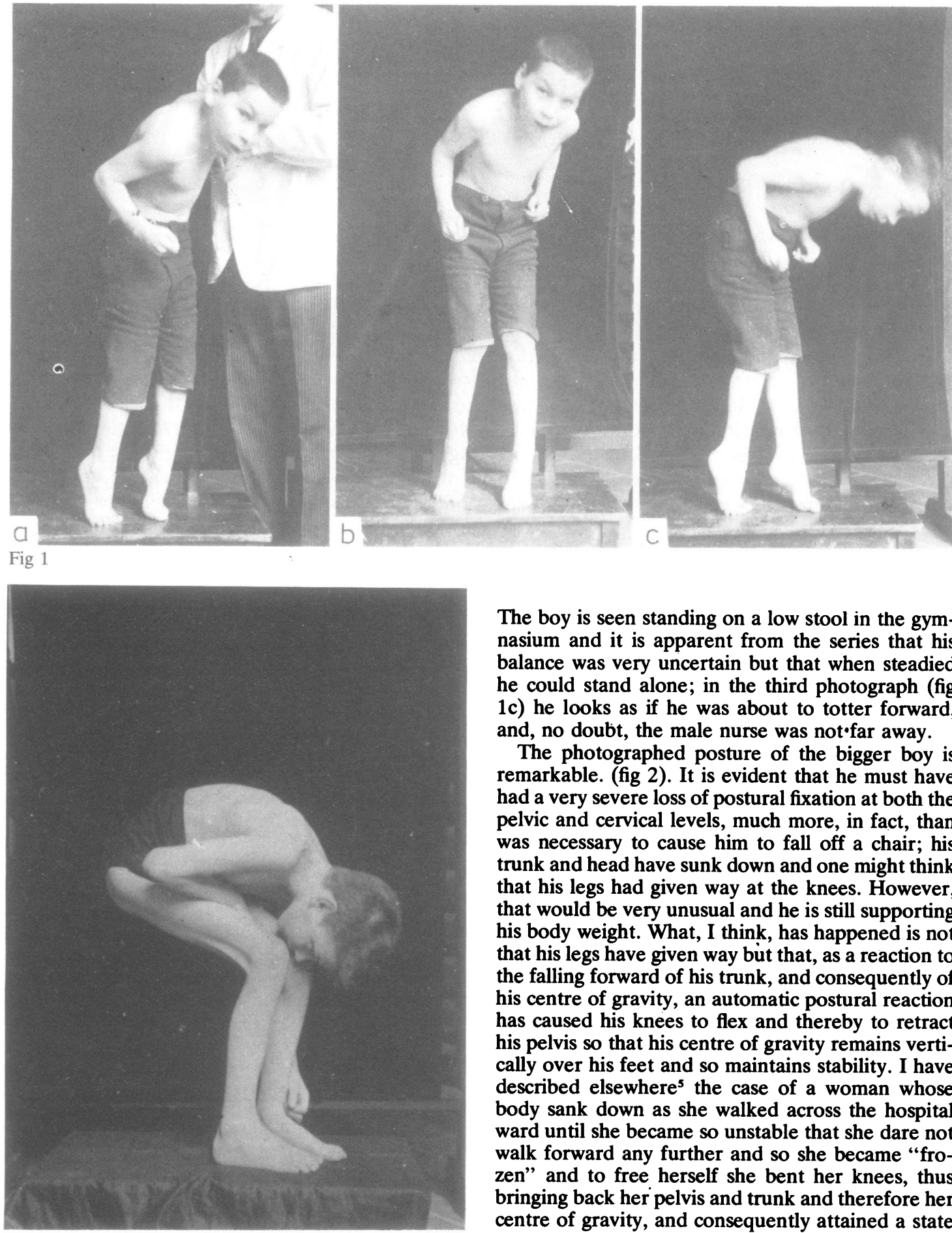

The boy is seen standing on a low stool in the gymnasium and it is apparent from the series that his balance was very uncertain but that when steadied he could stand alone; in the third photograph (fig 1c) he looks as if he was about to totter forward, and, no doubt, the male nurse was not $\cdot$ far away.

The photographed posture of the bigger boy is remarkable. (fig 2). It is evident that he must have had a very severe loss of postural fixation at both the pelvic and cervical levels, much more, in fact, than was necessary to cause him to fall off a chair; his trunk and head have sunk down and one might think that his legs had given way at the knees. However, that would be very unusual and he is still supporting his body weight. What, I think, has happened is not that his legs have given way but that, as a reaction to the falling forward of his trunk, and consequently of his centre of gravity, an automatic postural reaction has caused his knees to flex and thereby to retract his pelvis so that his centre of gravity remains vertically over his feet and so maintains stability. I have described elsewhere ${ }^{5}$ the case of a woman whose body sank down as she walked across the hospital ward until she became so unstable that she dare not walk forward any further and so she became "frozen" and to free herself she bent her knees, thus bringing back her pelvis and trunk and therefore her centre of gravity, and consequently attained a state of stability pending the arrival of help. 
Comparing the two cases from the physiological aspect, the posture of the second boy appears to be a purely "negative" syndrome, while that of the first boy presents the usual mixture of positive and negative elements, - extensive rigidity complicated by loss of postural fixation at the pelvis. Postures comparable to the former have been associated in experimental monkeys with extensive bilateral pallidal lesions, ${ }^{67}$ and in the human subject similar states have been accompanied by extensive pallidal degeneration. In the younger boy the loss of postural fixation is indicative of bilateral pallidal lesions less severe than those of his companion, while the rigidity can be ascribed (tentatively) to bilateral degeneration of the putamina acting as a "releasing" lesion to permit over-activity in parts of the pallida that are still competent. It is not likely that all these disorders are anatomical: the most constant and most characteristic pathological lesion in encephalitis lethargica was the damage to the substantia nigra, which is the principal source of dopamine, and so, to the effects of the anatomical lesions of the striatum and pallidum must have been added the functional effects of a deficiency of their neuro-transmitter.

To return to the photograph, (fig 2), if the second boy fell forward with his head down he would be in what has been called the "somersault" posture ${ }^{8}$ or, by Denny-Brown ${ }^{6}$ (in the monkey) the pallidal posture, but it would be more correct to say the "lack of pallida" posture. Denny-Brown had never seen this posture in the human subject (private communication), and I have never met with it except in the post-encephalitic state.

These photographs recall the state of knowledge of the postural function sixty years ago, in one of its most active periods. The neuro-muscular activity which supports the body performs a very fundamental function, but neurology was slow to recognise it and slow to appreciate the nature of its numerous disorders, negative and positive. Hughlings Jackson and his contemporaries hardly ever mentioned it, and the word "posture" does not even appear in the index of the two volumes of Jackson's "Selected Writings". If they paid any attention to it at all they regarded it as part of the motor function, and not as a function in its own right with motor components (postural movements), and, in fact, this attitude is still widely prevalent.

Walshe's observations, already mentioned, and then the reflexes of Magnus and de Kleijn and the discovery of their presence in the human subject ${ }^{10}$ must have given a great impetus to the recognition of the fact that postural activity and the resulting postural states were mostly automatic. The aftereffects of encephalitis lethargica offered a great opportunity to study the part played by the basal ganglia but it was not taken up at the time from which these photographs date, nor until a good many years later. ${ }^{11}$

\section{References}

' Holmes G. The clinical symptoms of cerebellar disease and their interpretation. $\mathrm{Br}$ Med J 1922;1:1177, 1231, and 2:59, 111.

${ }^{2}$ Walshe FMR. On certain tonic or postural reflexes in hemiplegia. Brain 1923;46:1-37.

${ }^{3}$ Walshe FMR. On variations in the form of reflex movements notably the Babinski plantar response, under different degrees of spasticity and under the influence of Magnus and de Kleijn's tonic neck reflex. Brain 1923;46:281-300.

4Walshe FMR. Review of Magnus's "Körperstellung". Brain 1924;47:383-390.

5 Martin J Purdon. The Basal Ganglia and Posture. London, Pitman 1967.

- Denny-Brown D. The basal ganglia and their relation to disorders of movement. Lancet 1960;2:1099-1105 and 1155-62.

${ }^{7}$ Richter R. Degeneration of the basal ganglia in monkeys from chronic carbon disulfide poisoning. J Neuropathol Exp Neurol $1945 ; 4: 324$

${ }^{8}$ Carpenter MB, Whittier J, Mettler FA. Analysis of choreoid hyperkinesia in the Rhesus monkey. J Comp Neurol 1950;92:293.

- Schaltenbrandt G, Normale Bewegungs- und Lagereackionen bei Kindern, $Z$ Nervenheilk 1925;87:23-59.

${ }^{10}$ Hellebrandt FA, Schade M, Carns ML. Methods of evoking the tonic neck reflexes in normal human subjects. $J$ Phys Med 1962;41:90-139.

" Martin JP, Hurwitz LJ, Finlayson MH. The negative symptoms of basal gangliar disease. Lancet 1962;2:1 and 62 . 